\title{
Home visits to frail elderly can save money and
} angst

\author{
Cite as: CMAJ 2017 April 18;189:E579-80. doi: 10.1503/cmaj.1095397
}

W hen an elderly woman in British Columbia suffering with terminal multiple myeloma and pneumonia suddenly began struggling to breathe, her physician knew the end was near.

"She was dying a choking painful death," recalled Dr. Ted Rosenberg, a Victoria-based specialist in community medicine with a focus in geriatrics. "I knew this [palliative patient] did not want to go to hospital - she made that very clear so I came to see her in her home."

Hydromorphone and an anti-anxiety drug were administered, and the woman passed away peacefully according to her wishes - in her home and with her daughter by her side.

Frail elderly individuals - such as those with mobility problems or cognitive impairment - often have difficulty regularly accessing health care. A decreasing number of physicians offer home visits, and even when seniors do make it into a clinic, there's often insufficient time to address their comorbidities.

With this in mind, Rosenberg developed his Home Team Medical practice in 2003 aimed at keeping elderly patients in their homes whenever possible - and saving the health care system the expenses of acute care, which can add up to $\$ 2000$ a day.

"I [get] a much better assessment of people in their own environment," he said. "The clinical setting may or may not accurately reflect how they are managing at home, and what their needs are." His team includes a registered nurse, a physiotherapist, a rehabilitation aid, a coordinator of patient care and, more recently, two other primary care physicians.

$\mathrm{BC}$ has one of the most rapidly aging populations in Canada with $18 \%$ of the population currently 65 or over - a number expected to reach $24 \%$ by 2031 , according to provincial government statistics.

BC Seniors Advocate Isobel MacKenzie says half of those over age 85 live alone and many are frail, making it challenging for them to see a physician. "If you are a senior who can't make it into the doctor's office, your only option is to go to the emergency department unless your doctor does house calls - and fewer and fewer doctors are doing house calls."

Seniors don't visit the emergency department more often than other demographics, MacKenzie notes, but once there, $27.5 \%$ are admitted to hospital, compared with $8 \%$ of those under age 65 .
Not only is this an added cost for the system, but hospitalized seniors risk infection, delirium and deconditioning.

Rosenberg's model offers an alternative to a health care system straining as baby boomers age. A 2012 study in the Journal of the American Geriatrics Society followed his 300 patients for one year, demonstrating a nearly $40 \%$ reduction in hospital admissions, a $37 \%$ decrease in length of hospital stay and $20 \%$ fewer visits to the emergency department compared to the year before they entered the Home Team Medical practice.

"It works out to [an average of] four fewer days of acute [hospital] care per patient per year... [or] $\$ 6000$ to $\$ 8000$

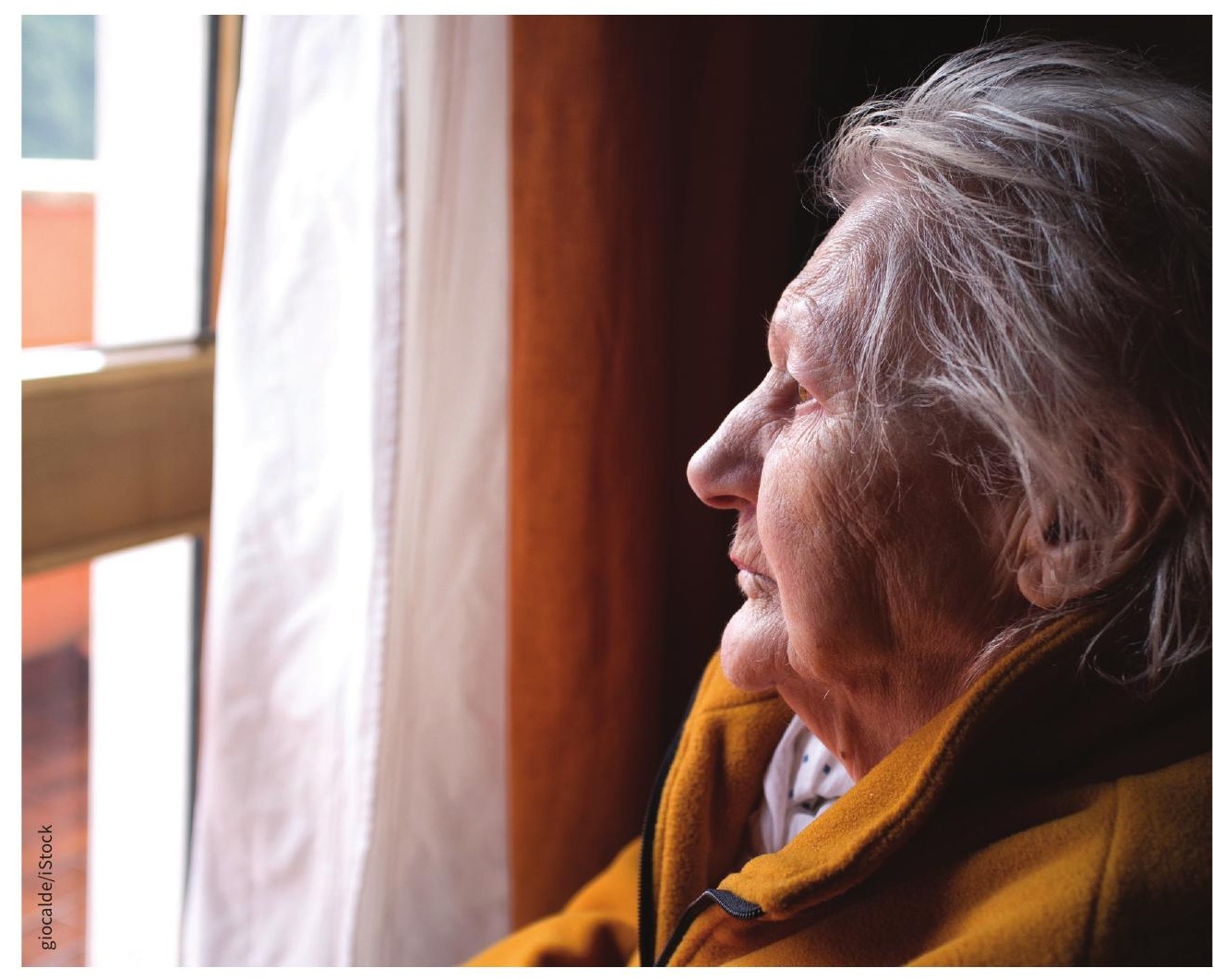

Half of British Columbians over the age of 85 live at home and many are frail. 
annually," said Rosenberg. He also facilitates between $40 \%$ and $50 \%$ of his patients dying at home - an option that saves on end-of-life hospital care.

Patients in Rosenberg's practice can also access non-publicly funded care from a gerontological registered nurse, a physiotherapist and a rehabilitation aid, all of whom come to see patients in their homes on an as-needed basis. Clients who require frequent access to this team can pay an annual fee of $\$ 1850$, while those who require less assistance can pay for each visit individually. All medical expenses are fully funded by the provincial government health plan, which reimburses doctors $\$ 112$ for each house visit as opposed to the typical $\$ 28$ for an office visit.

Rosenberg is not the only one working with homebound seniors in the province. Ten part-time physicians and two nurse practitioners in Vancouver Coastal Health's Home ViVE program see between 400 and 500 frail Vancouverites over 80, for example, something BC's Seniors Advocate MacKenzie believes makes a difference for this population.
"If frail housebound seniors have physicians who visit them regularly or when needed... you're going to be able divert the need to go to emergency because you've caught something earlier in the trajectory," MacKenzie said.

Rosenberg agrees, and says he hopes his research could help make the case for multidisciplinary home-based care to be fully covered by the province.

Brit Cooper-Jones and Katelyn

Verstraten, Vancouver, British

Columbia 